NBER WORKING PAPER SERIES

A GENERAL RATIONALE FOR A GOVERNMENTAL ROLE IN THE RELIEF OF LARGE RISKS

\author{
Steven Shavell \\ Working Paper 20192 \\ http://www.nber.org/papers/w20192 \\ NATIONAL BUREAU OF ECONOMIC RESEARCH \\ 1050 Massachusetts Avenue \\ Cambridge, MA 02138 \\ June 2014
}

I thank Peter Diamond, Georges Dionne, Kenneth Froot, Louis Kaplow, and A. Mitchell Polinsky for comments, Michael Belinsky and Jonathan Borowsky for research assistance, and the John M. Olin Center for Law, Economics, and Business at Harvard University for research support. The views expressed herein are those of the author and do not necessarily reflect the views of the National Bureau of Economic Research.

NBER working papers are circulated for discussion and comment purposes. They have not been peerreviewed or been subject to the review by the NBER Board of Directors that accompanies official NBER publications.

(C) 2014 by Steven Shavell. All rights reserved. Short sections of text, not to exceed two paragraphs, may be quoted without explicit permission provided that full credit, including $\bigcirc$ notice, is given to the source. 
A General Rationale for a Governmental Role in the Relief of Large Risks

Steven Shavell

NBER Working Paper No. 20192

June 2014

JEL No. D6,D8,K2

\section{ABSTRACT}

The government often provides relief against large risks, such as disasters. A simple, general rationale for this role of government is considered here that applies even when private contracting to share risks is not subject to market imperfections. Specifically, the optimal private sharing of risks will not result in complete coverage against them when they are sufficiently large. Hence, when such risks eventuate, the marginal utility to individuals of governmental relief may exceed the marginal value of public goods. Consequently, social welfare may be raised if the government reduces public goods expenditures and directs these freed resources toward individuals who have suffered losses.

\section{Steven Shavell}

Harvard Law School

1575 Massachusetts Avenue

Hauser Hall 508

Cambridge, MA 02138

and NBER

shavell@law.harvard.edu

An online appendix is available at:

http://www.nber.org/data-appendix/w20192 


\title{
A General Rationale for a Governmental Role in the Relief of Large Risks
}

\author{
Steven Shavell ${ }^{*}$ \\ Forthcoming in the Journal of Risk and Uncertainty \\ JEL classifications: D6, D8, K2
}

The government often provides relief against large risks, such as disasters. A simple, general rationale for this role of government is considered here that applies even when private contracting to share risks is not subject to market imperfections. Specifically, the optimal private sharing of risks will not result in complete coverage against them when they are sufficiently large. Hence, when such risks eventuate, the marginal utility to individuals of governmental relief may exceed the marginal value of public goods. Consequently, social welfare may be raised if the government reduces public goods expenditures and directs these freed resources toward individuals who have suffered losses.

\section{Introduction}

The government plays a well-recognized role in providing relief against many large risks. Notably, the government traditionally furnishes disaster assistance and subsidizes markets for flood and earthquake insurance. ${ }^{1}$

That the government is often observed to ameliorate substantial risks naturally raises the question about the justification for that policy. I consider here a general rationale for the government to relieve significant risks that applies even

\footnotetext{
* Samuel R. Rosenthal Professor of Law and Economics, Harvard Law School, and Research Associate, National Bureau of Economic Research. I thank Peter Diamond, Georges Dionne, Kenneth Froot, Louis Kaplow, and A. Mitchell Polinsky for comments, Michael Belinsky and Jonathan Borowsky for research assistance, and the John M. Olin Center for Law, Economics, and Business at Harvard University for research support.

${ }^{1}$ On the role of the government in disaster assistance, see generally the historical account of Moss (1999) and, for example, the website of the Federal Emergency Management Agency (FEMA), www.fema.gov; on government programs to foster flood and earthquake insurance, see FEMA (2002) and the website of the California Earthquake Authority, www.earthquakeauthority.com. The government also promotes and furnishes other types of insurance, such as disability and health insurance, of course, but the basis for these types of aid appears to be different from that discussed here.
} 
when, as I will assume, private contracting to share risks is perfect (unimpeded by transaction costs, asymmetric information, externalities, or other sources of market failure). The rationale, in essence, is that the optimal private sharing of very large risks will not result in complete coverage against them. Therefore, when the risks eventuate, the marginal utility to individuals of relief from the government will be high in a relative sense and may exceed the marginal value to individuals of public goods. Consequently, social welfare may be raised if the government reduces public goods expenditures and directs these freed resources toward individuals who have suffered losses.

Although the foregoing argument is straightforward, it does not seem to have been clearly articulated before. I develop it below employing a simple model involving a population of identical individuals, a single consumption good, a risk of loss of the consumption good-where this accident risk may be correlated across individuals_-frictionless joint contracting among all individuals to share risk, and a government that produces a public good.

Two times are considered in the model: time 1, before risk resolves itself, and time 2, after possible accident losses have occurred. At time 1, individuals pay a tax to finance the public good and they contract in a privately-optimal way to share risk. Their best risk-sharing contracts do not lead to full coverage against loss. Indeed, in the extreme case of a single, economy-wide risk (a flood that affects everyone), contracting would not result in any coverage; the privately-optimal risk-sharing contract would be the null contract.

The main results shown are these. First, there exists a welfare-enhancing policy under which the government grants relief to accident victims whenever the number of accidents in the population is sufficiently high. ${ }^{2}$ Welfare is enhanced

\footnotetext{
2 The policy of government relief will, however, result in some crowding out of payments made to accident victims under private risk-sharing contracts.
} 
for the reason I noted above: when the number of accidents is high, the wealth of accident victims after optimal risk-sharing is relatively low and their marginal utility of income is relatively high, implying that they will be made better off if resources are shifted from public goods to them by the making of relief payments. Second, a policy of government relief exists that achieves the first-best outcome in terms of both risk-sharing and provision of public goods. Third, a policy of government subsidy of risk-sharing contracts (analogous to the subsidy of insurance contracts) may provide social benefits similar to those of government relief. ${ }^{3}$ And fourth, a policy under which taxes are lowered appropriately as the number of accidents increases allows the first-best outcome to be achieved without government relief or the subsidy of risk-sharing contracts.

The general justification for government aid in the event of large risks that is examined in the model seems consistent with actual policy in at least an approximate sense. On one hand, the important risks mentioned above that the government helps to alleviate have the character that they may affect many individuals simultaneously; this is frequently true of disasters. On the other hand, private insurance coverage against these positively correlated risks tends to be circumscribed, ${ }^{4}$ making it plausible that a shift of resources from the provision of public goods to those who have suffered losses would often be socially desirable.

The rationale for government help in the face of large, correlated risks presented here is different from those discussed in prior writing to my

${ }^{3}$ As will be seen, a well-designed ex post subsidy of coverage payments made to accident victims will be socially beneficial, but an ex ante subsidy of risk-sharing contracts cannot improve social welfare because it does not make public goods expenditures depend on the occurrence of accidents.

\footnotetext{
${ }^{4}$ Regarding the paucity (and high cost) of private insurance coverage against catastrophic events, see generally Froot (1999, 2001), and also, for example, Jaffee and Russell (1997) and Cummins (2006). As Froot emphasizes, the scarcity of coverage due to these correlated losses is significant, even though one might have expected otherwise, given the existence of the reinsurance industry and the size of global capital markets.
} 
knowledge. First, some authors who have stressed that insurance coverage against disasters is limited suggest that this problem per se justifies government relief. ${ }^{5}$ But that conclusion does not follow when the limited coverage is the result of privately-optimal risk sharing — government relief is warranted only if the government provides public goods. If the government has no need to provide public goods, the government will not have command over resources to advantageously draw upon to furnish relief when privately-optimal risk sharing leaves individuals wanting. ${ }^{6}$

A second reason for government aid is premised on the assumption that the government is uniquely able to distribute risk over the entire population through the medium of the income tax system. Under this assumption, when the government assumes a risk, like that of a natural disaster, the impact on the individual taxpayer in a large population is small, making the government a desirable bearer of risk. ${ }^{7}$ The foregoing argument is different from the one I consider because I assume that all individuals in the population are able to jointly contract to share risk. Hence, in the model examined below, the government does not enjoy any advantage over the private sector in the spreading of private risks across the population.

\footnotetext{
${ }^{5}$ See, for example, the discussion of the coverage of terrorism risk in Cummins (2006), p. 375.

${ }^{6}$ The reader can verify that if there is no demand for public goods, the first-best outcome described in Proposition 1 is achieved under privately optimal risk-sharing described in Proposition 2.

${ }^{7}$ This argument is developed by Arrow and Lind (1970), who show under certain assumptions not only that the risk-bearing cost per individual tends to zero with the population size, but also that the aggregate risk-bearing cost tends to zero.
} 
A third justification for government relief is that individuals may systematically underestimate risk, leading them to underinsure. ${ }^{8}$ A fourth justification is adverse selection, for it can reduce or eliminate private coverage even though coverage would be socially desirable. ${ }^{9}$ These two reasons for government aid are obviously different from that advanced here.

Finally, let me comment on writing that is skeptical of the basis for a governmental role in relieving large risks. The most commonly made argument against a governmental role is an expression of the general view that governmental intervention in reasonably well-functioning markets-here insurance markets — tends to be undesirable. ${ }^{10}$ This classic laissez-faire belief, though, is not necessarily valid when applied to insurance markets. As I have emphasized is the case in the model developed here, even if private markets for risk-sharing function efficiently, the government should sometimes act to relieve risk using funds that otherwise would finance public goods.

More particular arguments are also made against government relief against risk. One of note is that although problems of moral hazard (for example, an insured person inefficiently building a house in an area vulnerable to floods) may lead to limited coverage against risk, moral hazard is not a justification for government relief. Moral hazard is in fact generally exacerbated by provision of government relief. ${ }^{11}$ Such problems are serious ones that should clearly be taken into account in the design of policies for relief, but the model here abstracts from them.

\footnotetext{
${ }^{8}$ See, for example, Kunreuther, et al (1978).

${ }^{9}$ See, for example, Dionne, Doherty, and Fombaron (2000) for a survey on adverse selection in insurance markets.

${ }^{10}$ See, for example, Priest (1999); and see Cummins (2006), who also emphasizes the point that government coverage can supplant private coverage.

${ }^{11}$ See Kaplow (1991).
} 


\section{The Model}

2.1 Basic assumptions. There is an economy of $n$ individuals with identical utility functions. Each individual derives utility from consumption of a single good, wealth, with respect to which he is risk-averse, and also from a public good. In particular, let $i$ be the index of a person and define

$$
\begin{aligned}
y_{i} & =\text { wealth of person } i ; y_{i} \geq 0 ; \\
u\left(y_{i}\right) & =\text { utility of person } i \text { from wealth } y_{i} ; u^{\prime}\left(y_{i}\right)>0 \text { and } u^{\prime \prime}\left(y_{i}\right)<0 ; \\
z & =\text { quantity of a public good; } z \geq 0 ; \text { and } \\
v(z) & =\text { utility of each person from the public good; } v^{\prime}(z)>0 \text { and } v^{\prime \prime}(z)<0 .
\end{aligned}
$$

All individuals obtain utility simultaneously from $z$ because it is a public good.

Let the total utility of an individual be given by

$$
w\left(y_{i}, z\right)=u\left(y_{i}\right)+v(z) .
$$

The assumption that utility from wealth and from the public good are separable is made mainly for convenience. ${ }^{12}$ Now let me describe the amount of wealth in the economy and the risks of accidents. Each person has identical initial wealth; let

$$
y_{0}=\text { initial endowment of wealth of each person; } y_{0}>0 \text {. }
$$

Individuals face a risk of an accident, where

$$
h=\text { harm that is suffered by an individual if an accident occurs; } 0<h<y_{0} \text {. }
$$

The harm $h$ is a diminution in wealth of fixed magnitude and is the same for all individuals. ${ }^{13}$ Let

$$
s_{i}=0 \text { if person } i \text { does not have an accident; }
$$

\footnotetext{
12 The importance of this assumption is that it implies that the socially optimal level of individual consumption and of the public good are each rising in total wealth.

${ }^{13}$ I do not consider non-monetary harm, such as due to pain and suffering from an injury. In the central case of non-monetary harm-in which the harm is a decline in utility but does not involve any change in the utility from wealth - there is no demand for insurance. See Cook and Graham (1977). Hence, in that case, the issue studied in the model would be moot; and if harm were both a monetary loss and a utility loss, the results to be obtained here would be unaltered.
} 
$=1$ if person $i$ does have an accident;

and call $s=\left(s_{1}, \ldots, s_{n}\right)$ a complete accident state. Let

$$
\begin{aligned}
p(s) & =\text { probability of } s ; \text { and } \\
p_{m} & =\text { probability that exactly } m \text { accidents occur; } m=0,1, \ldots, n ;
\end{aligned}
$$

so that $p_{m}$ is the sum of $p(s)$ over the $s$ such that exactly $m$ accidents occur. I will call the event in which exactly $m$ accidents occur an accident event $m$ and will assume that there are at least two accident events (including the no accident event) that occur with positive probability (otherwise there would be no uncertainty in the economy). In an accident event $m$, total wealth in the economy will be $n y_{0}-m h$ since $n y_{0}$ is total initial wealth and $m h$ is total accident losses.

I assume that wealth can be converted into the public good on a one-forone basis, so that if $z$ units of wealth are allocated to provision of the public good, then $z$ will be the level of the public good.

To describe an allocation of total wealth given an accident event $m$, let $y_{i}(m)=$ wealth allocated to person $i$ in accident event $m ; y_{i}(m) \geq 0$; $z(m)=$ quantity of the public good in accident event $m ; z(m) \geq 0$. A feasible allocation given accident event $m$ is any $\left(y_{1}(m), \ldots, y_{n}(m), z(m)\right)$ such that $^{14}$

$$
\left(\sum_{i} y_{i}(m)\right)+z(m)=n y_{0}-m h .
$$

A feasible allocation scheme is a feasible allocation for each accident event $m$.

I make two additional assumptions (that will be seen to guarantee that the best feasible allocation schemes involve positive levels of both consumption of wealth and the public good). First,

(2) $\quad u^{\prime}(0)>n v^{\prime}\left(n\left(y_{o}-h\right)\right)$,

${ }^{14}$ In considering only the feasible allocations given by (1), I am making two harmless simplifications: that total wealth is exhausted by an allocation; and that allocations do not depend on complete accident states (rather than only on accident events $m$ ). 
that is, the marginal utility of consumption when no wealth is allocated to consumption exceeds the marginal social utility of the public good when all wealth is allocated to the public good (and $n$ accidents occur). Second, (3) $u^{\prime}\left(y_{0}-h\right)<v^{\prime}(0)$,

the marginal utility of the public good when no wealth is allocated to it exceeds the marginal utility of consumption even when a person has suffered an accident loss.

Finally, I assume that social welfare is the expected utility of the representative individual, that is, the expected utility of an individual, assuming that each of the identical individuals enjoys the same expected utility.

2.2 First-best solution. The social welfare-maximizing feasible allocation scheme, under which each individual obtains the same expected utility, will be denoted $\left(y_{1}^{*}(m), \ldots, y_{n}^{*}(m), z^{*}(m)\right), m=0, \ldots, n$. It is described as follows.

Proposition 1. Under the first-best allocation scheme,

(a) in any accident event $m$, each individual's level of consumption $y_{i}{ }^{*}(m)$ is the same, equal to a common level $y^{*}(m)=y_{o}-z^{*}(m) / n-(m / n) h$;

(b) the level of each individual's consumption $y^{*}(m)$ as well as the level of the public good $z^{*}(m)$ is positive and they are strictly decreasing in the number of accidents, as determined by (9) below.

Notes. The explanation for this result is, in essence, that since individuals are risk averse and identical, it must be optimal for consumption levels to be equal in any accident event. Further, because the total wealth available for consumption in an accident event $m$ is $n y_{o}-z^{*}(m)-m h$, the per capita amount available for consumption is $y_{o}-z^{*}(m) / n-(m / n) h$. And since total available wealth falls as the number of accidents rises, it is desirable for both the total allocation of wealth toward consumption and that toward public goods to be lowered, in order to maintain equality between the marginal social value of consumption and the 
marginal social value of public goods (in effect, consumption and the public good are both normal goods for the representative person).

Proof: The problem is to maximize the expected utility of an individual subject to the feasibility constraints (1) and to the constraint that the expected utility of each individual is the same. To this end, I will consider a related problem: maximize the sum of the expected utilities of the $n$ individuals subject only to the feasibility constraints. I will show that the solution to this related problem is such that each individual's expected utility is the same. It will follow that the solution to the related problem must be the solution to the given problem. $^{15}$

Turning therefore to the problem of maximizing the sum of the expected utilities of individuals, note that the expected utility of person $i$ under a feasible allocation scheme is

$$
\sum_{m} p_{m} w\left(y_{i}(m), z(m)\right)=\sum_{m} p_{m}\left[u\left(y_{i}(m)\right)+v(z(m))\right] .
$$

The sum of expected utilities over the population is therefore

$$
\sum_{i} \sum_{m} p_{m}\left[u\left(y_{i}(m)\right)+v(z(m))\right]=\sum_{m} p_{m} \sum_{i}\left[u\left(y_{i}(m)\right)+v(z(m))\right] .
$$

Hence, to maximize the sum of expected utilities over feasible allocation schemes it is necessary and sufficient for each accident event $m$ to maximize

$$
\sum_{i}\left[u\left(y_{i}(m)\right)+v(z(m))\right]=\left[\sum_{i} u\left(y_{i}(m)\right)\right]+n v(z(m)),
$$

subject to the feasibility constraints (1). Substituting for $z(m)$ using (1), the problem is to maximize

(7) $\left[\sum_{i} u\left(y_{i}(m)\right)\right]+n v\left(n y_{0}-m h-\sum_{i} y_{i}(m)\right)$

over $y_{i}(m)$. Since (7) is concave in $y_{i}(m)$, the optimum is uniquely determined by

$$
u^{\prime}\left(y_{i}(m)\right)=n v^{\prime}\left(n y_{0}-m h-\sum_{i} y_{i}(m)\right)
$$

${ }^{15}$ In particular, let the feasible allocation scheme that maximizes the sum of expected utilities be denoted $S$, and let $e$ be the expected utility of each person under this scheme, so that ne is the maximum sum of expected utilities. If $S$ is not the scheme that maximizes the expected utility of each person subject to the constraint that each has the same expected utility, there must exist another scheme $S^{\prime}$ under which each person obtains expected utility $e^{\prime}>e$. But then $n e^{\prime}>$ $n e$, contradicting the assumption that $S$ maximized the sum of expected utilities. 
if there is an interior solution (which I will show to be so below). Because (8) must hold for all $i$ and the right side of (8) is independent of $i$, we know that $u^{\prime}\left(y_{i}(m)\right)=u^{\prime}\left(y_{j}(m)\right)$ and thus that $y_{i}(m)=y_{j}(m)$ for any $j \neq i$. Consequently, there is a common value $y(m)$ of the $y_{i}(m)$. Accordingly, (8) becomes

(9) $\quad u^{\prime}(y(m))=n v^{\prime}\left(n y_{0}-m h-n y(m)\right)$;

it is this condition that determines $y^{*}(m)$ and thus (using (1)), we know that $z^{*}(m)$ $=n y_{o}-m h-n y^{*}(m)$ and that $y^{*}(m)=y_{o}-z^{*}(m) / n-(m / n) h$. The interpretation of (9) is that the marginal utility of consumption equals $n$ times the marginal utility of the public good; the factor $n$ enters because if each individual changes his consumption by one unit of wealth, the level of the public good must change by $n$ units. To show that a solution to (9) exists and that $y^{*}(m)$ and $z^{*}(m)$ are positive, observe that when $y(m)$ is 0 , the left side of (9) is $u^{\prime}(0)$ and the right is $n v^{\prime}\left(n y_{0}-\right.$ $m h)$. Further, (2) implies that

(10) $u^{\prime}(0)>n v^{\prime}\left(n y_{0}-m h\right)$.

Observe as well that if $z(m)$ is 0 , the left side of $(9)$ is $u^{\prime}\left(y_{0}-(m / n) h\right)$ and the right side is $n v^{\prime}(0)$. But (3) implies that

(11) $u^{\prime}\left(y_{0}-(m / n) h\right)<n v^{\prime}(0)$.

These two inequalities and the facts that $u^{\prime}(y(m))$ is decreasing in $y(m)$ and that $n v^{\prime}\left(n y_{0}-m h-n y(m)\right)$ is increasing in $y(m)$ imply that the claims about the solution to (9) must hold.

To determine how $y^{*}(m)$ and $z^{*}(m)$ depend on $m$, it will be convenient to ask how they depend on total wealth, $n y_{0}-m h$. To this end, in this paragraph denote $y^{*}(m)$ simply by $y^{*}, z^{*}(m)$ by $z^{*}$, and total wealth by $k$. Then (9) can be rewritten as $u^{\prime}\left(y^{*}\right)=n v^{\prime}\left(k-n y^{*}\right)$. Implicitly differentiating this equation with respect to $k$, we obtain

$$
u^{\prime \prime}\left(y^{*}\right) y^{*^{\prime}}(k)=n\left(1-n y^{*^{\prime}}(k)\right) v^{\prime \prime}\left(k-n y^{*}\right)
$$

or

(13) $y^{* \prime}(k)=n v^{\prime \prime}\left(k-n y^{*}\right) /\left(n^{2} v^{\prime \prime}\left(k-n y^{*}\right)+u^{\prime \prime}\left(y^{*}\right)\right)$. 


\section{Hence}

(14) $y^{*^{\prime}}(k)>0$.

and thus $d y^{*}(m) / d m<0$ as claimed. ${ }^{16}$ Furthermore, since $z^{*}=k-n y^{*}$, (15) $z^{*^{\prime}}(k)=1-n y^{* \prime}(k)>0$,

where the inequality follows from (11). Thus, $d z^{*}(m) / d m<0$ as is also claimed. ${ }^{17}$ Q. E. D.

\subsection{Outcome with private risk-sharing and taxation to provide the public} good. For the purposes of this and later sections, I will make an assumption about the distribution of complete accident states $s=\left(s_{1}, \ldots, s_{n}\right)$. (It was not necessary to make assumptions about the distribution of $s$ to characterize the first-best solution.) Let

$p_{i}(0, j)=$ probability that person $i$ does not suffer an accident loss but that exactly $j$ others do suffer an accident loss.

Thus $p_{i}(0, j)$ is the sum of $p(s)$ over $s$ such that $s_{i}=0$ and there are exactly $j s_{k}$ with $s_{k}=1$. Likewise, let

$p_{i}(1, j)=$ probability that person $i$ suffers an accident loss and that exactly $j$ others also suffer an accident loss.

I make the following symmetry of risk assumption: For any two individuals $i$ and $k, p_{i}(0, j)=p_{k}(0, j)$ and $p_{i}(1, j)=p_{k}(1, j)$ for all $j$. Let, $p(0, j)$ and $p(1, j)$ denote these common probabilities across individuals.

The symmetry assumption is satisfied by many types of distributions of risks, notably risks that are correlated in different ways as well as independent risks, as several examples will illustrate: (a) Suppose that there is perfect correlation of risks in the entire population — that all $n$ individuals will

\footnotetext{
16 This follows because $d y^{*}(m) / d m=\left(d y^{*}(m) / d k\right)(d k / d m)$. But $\left(d y^{*}(m) / d k\right)>0$ by (13) and $d k / d m=-h<0$.

${ }^{17}$ This follows by the logic of the previous note.
} 
simultaneously suffer an accident loss with probability p; otherwise none will suffer an accident loss. Then the symmetry assumption is satisfied since the formulas for $p_{i}(1, j)$ and $p_{i}(0, j)$ do not depend on $i .^{18}$ (b) Now suppose that there is perfect correlation in a subgroup of the population - that some subgroup of $m<$ $n$ individuals will simultaneously suffer an accident loss with probability $p$ and that each individual has an equal likelihood of being in such a subgroup of accident victims; otherwise none will suffer an accident loss. It is easy to verify here as well that the symmetry assumption is satisfied. ${ }^{19}$ (c) Last, suppose that each individual has an independent probability $p$ of being an accident victim. Then again the symmetry assumption is satisfied. ${ }^{20}$

The symmetry assumption implies the following.

Remark. If the symmetry assumption holds, then conditional on the occurrence of $m$ accidents, the probability that any given person suffered an accident loss is $m / n$.

To verify this claim, observe that the conditional probability in question for any person $i$ is $p_{i}(1, m-1) / p_{m}$, which equals $p(1, m-1) / p_{m}$. Call this common conditional probability $q$. The expected number of people who experienced a loss must then be $n q$, but the actual number who suffer a loss is $m$. Hence, $n q=m$, so that $q=m / n$ as asserted.

The reason that I make the symmetry of risk assumption is that it implies that the expected utility of all individuals will be the same. Therefore, social

18 In this case, for each $i, p_{i}(1, n-1)=p$ and $p_{i}(1, j)=0$ for $j<n-1$, and also $p_{i}(0,0)=$ $1-p$ and $p(0, j)=0$ for $j \geq 1$.

19 For each $i, p_{i}(1, m-1)=(m / n) p$ and $p_{i}(1, j)=0$ for $j \neq m-1$, and also $p_{i}(0,0)=1-p$, $p_{i}(0, m)=(1-m / n) p$, and $p(0, j)=0$ for $j \neq 0$ or $m$. Similarly, the symmetry assumption could hold in a variation of this example, in which the possible subgroups of $m$ individuals are neighbors or are in some other manner restricted.

${ }^{20}$ For each $i, p_{i}(1, j)=p^{j+1}(1-p)^{n-j-1}(n ! /[(j+1) !(n-j-1) !])$ and $p_{i}(0, j)=p^{j}(1-p)^{n-}$ ${ }^{j}(n ! /[j !(n-j) !])$. 
welfare in the model can be measured by the expected utility of the representative individual. ${ }^{21}$

Now let me describe the assumptions about a regime in which the government imposes a tax to finance the public good and in which individuals make contracts to share risk.

Specifically, let

$t=$ tax per person to finance the public good; $t \geq 0$, where $t$ is imposed at time 1 , before accidents might occur. The amount of the public good is therefore $n t$. The expected utility of each individual in the absence of any contracting is identical and given by

$$
\sum_{m} p_{m}\left[(1-(m / n)) u\left(y_{o}-t\right)+(m / n) u\left(y_{o}-t-h\right)+v(n t)\right] .
$$

The reason is that the symmetry assumption implies that conditional on the accident event $m$, each person faces the same probability of suffering a loss, $m / n$.

I assume that individuals also make a risk-sharing contract at time 1. Specifically, the contract involves all individuals and specifies an amount to be paid at time 2 if an individual did not suffer an accident loss and an amount to be received if an individual did suffer an accident loss, where these amounts may depend on the total number of accidents that occur. ${ }^{22}$ Define

${ }^{21}$ Nevertheless, the lessons from the model would carry over to a general context in which risks are not symmetric and differ across individuals. The reason is that the main argument to be developed depends on two factors that are unrelated to the symmetric risk assumption, namely, (a) the point that privately-optimal risk-sharing contracts do not lead to full coverage against large risks and (b) the assumption that the government provides public goods.

${ }^{22}$ Other types of private risk-sharing contracts could be considered, notably contracts among only a subset of individuals, or contracts under which the payment received by an accident victim depends on the identity of other accident victims rather than just on their total number. However, examination of a different set of contracts would not alter the main qualitative conclusion to be reached - that the government can raise the expected utility of individuals by giving relief in certain circumstances. The reason, in essence, is that, whatever the nature of private contracting, it cannot control the expenditure of the government on public goods. 
$x(m)=$ amount paid by a person if he is not an accident victim and $m$ accidents occur;

$r(m)=$ amount received by a person if he is an accident victim and $m$ accidents occur.

For the contract to be feasible, we must have, for each $m$,

(17) $(n-m) x(m)=m r(m)$,

since $(n-m)$ individuals will pay $x(m)$ and $m$ individuals will receive $r(m)$. A contract will result in the same expected utility for all individuals due to the symmetry assumption, namely

(18) $\sum_{m} p_{m}\left[(1-(m / n)) u\left(y_{o}-t-x(m)\right)+(m / n) u\left(y_{o}-t-h+r(m)\right)+v(n t)\right]$.

I assume that individuals choose the contract that maximizes (18) subject to (17), which will be denoted by $x^{*}(m)$ and $r^{*}(m)$; I will call this the privately optimal risk-sharing contract.

I also assume that the government chooses the tax to maximize social welfare given that individuals choose the privately optimal risk-sharing contract (taking the tax as given).

The next result describes the outcome under private contracting and government taxation to finance the public good.

Proposition 2. Suppose that the government imposes the optimal tax to finance the public good.

(a) Then under the privately optimal risk-sharing contract, accident victims will receive $r^{*}(m)=(1-m / n) h$, so that they will absorb $m / n$ of their losses $h$, and individuals who are not accident victims will pay $x^{*}(m)=(m / n) h$.

(b) Consequently, the final wealth of all individuals will be the same in each accident event, namely, $y_{0}-t^{*}-(m / n) h$, and risk-sharing will be socially optimal given the level of public expenditures.

(c) The optimal tax $t^{*}$ is determined by (24) below. 
Notes. That the privately optimal risk-sharing contract results in equalization of wealth across all individuals for each accident event $m$ reflects the assumption that individuals are identical and are risk-averse. That this outcome is socially optimal given the level of expenditures on public goods is clear from the discussion of the first-best outcome in Proposition 1 (see (8)).

The amount of wealth that individuals enjoy is their per capita share of total wealth after subtraction of taxes collected and total accident losses. Note that the fraction $(1-m / n)$ of his loss received in compensation by an accident victim depends on the fraction $\mathrm{m} / \mathrm{n}$ of individuals in the population that suffer losses. Thus, in particular, if there is a catastrophic event in which a large fraction of individuals suffer losses, the proportion of losses received by victims will be small, and would be zero if all were victims ( $\mathrm{m} / \mathrm{n}$ would then equal 1$)$. Note too that in the standard case of independent risks where the individual accident probability is $p$, we know by the law of large numbers that if $n$ is sufficiently high, then $m / n$ is very likely to be within any specified small positive $\varepsilon$ of $p$. Hence, the amount received by victims is very likely to approximate $(1-p) h$ and the amount paid by those who are not victims is very likely to approximate $p h$. Thus, the outcome resembles that from the theory of insurance, for the premium for full coverage is the actuarially fair amount $p h$ and the net amount received by a victim is $h$ less his premium of $p h$ or $(1-p) h$.

Regarding the optimal tax, the condition (24) equates the marginal social value of the public good to $n$ times the expected marginal utility of wealth.

Proof. It is clear that, maximizing (18) subject to (17) is equivalent to maximizing

$$
\left[(1-(m / n)) u\left(y_{o}-t-x(m)\right)+(m / n) u\left(y_{o}-t-h+r(m)\right)\right.
$$

for each $m$ subject to (17). Using (17), this problem reduces to maximizing (20)

$$
\left[(1-(m / n)) u\left(y_{o}-t-x(m)\right)+(m / n) u\left(y_{o}-t-h+(n-m) x(m) / m\right)\right.
$$

over $x(m)$ for each $m$. The first-order condition for the optimal $x(m)$ reduces to 


$$
u^{\prime}\left(y_{0}-t-x(m)\right)=u^{\prime}\left(y_{0}-t-h+(n-m) x(m) / m\right)
$$

implying that $y_{0}-t-x(m)=y_{0}-t-h+(n-m) x(m) / m$, so that $x^{*}(m)=(m / n) h$ and thus $r^{*}(m)=(1-(m / n)) h$.

We therefore know that the expected utility of each person given optimal contracting is, using (18) and what we have just shown about the optimal contract,

$$
\sum_{m} p_{m}\left[u\left(y_{0}-t-(m / n) h\right)+v(n t)\right]=\left[\sum_{m} p_{m} u\left(y_{0}-t-(m / n) h\right)\right]+v(n t) .
$$

The optimal $t$ maximizes (22), the derivative of which is

$$
-\sum_{m} p_{m} u^{\prime}\left(y_{0}-t-(m / n) h\right)+n v^{\prime}(n t) \text {. }
$$

At $t=0$, (23) is $-\sum_{m} p_{m} u^{\prime}\left(y_{0}-(m / n) h\right)+n v^{\prime}(0)$, which (3) implies is positive.

Hence, $t^{*}$ must be positive, so it is determined by

(24) $\sum_{m} p_{m} u^{\prime}\left(y_{0}-t-(m / n) h\right)=n v^{\prime}(n t)$;

this equation has a unique solution since (22) is concave in $t$. Q. E. D.

2.4 Government relief. Let me now discuss why the expected utility of all individuals can be raised if the government gives financial relief to accident victims. Under the policy of no government relief just considered, the amount of the public good, and hence its marginal utility to an individual, is fixed. This implies that there should be an opportunity for the government to raise individuals’ welfare by shifting funds from public goods to relief for accident victims when there have been sufficiently many accidents, for then after receiving their payments under optimal risk-sharing contracts, their wealth will still be relatively low.

To amplify, suppose that

$g(m)$ = payment made by the government to each accident victim when $m$ is the total number of accident victims; $g(m) \geq 0$;

and assume that this payment is made regardless of any risk-sharing contract that the individual has concluded. Since $g(m)$ is paid to $m$ individuals, the total expense to the government is $m g(m)$, so that the level of public goods supplied will be $n t-m g(m)$ in accident event $m$. When individuals make a risk-sharing 
contract, they are assumed to know the government policy of relief. We have the following result.

Proposition 3. There exists a policy of government relief for accident victims that results in higher expected utility for all individuals than they enjoy under the policy of no relief described in Proposition 2. Specifically, suppose that the tax is the optimal tax $t^{*}$ under the policy of no relief and that positive relief is given to accident victims for all accident events $m$ where $m$ is sufficiently high, determined by (25) below, and where the amount of relief $g(m)$ satisfies (26) below. Then under the privately optimal risk-sharing contract, accident victims will receive $r^{*}(m)=(1-m / n)(h-g(m))$ and individuals who are not victims will pay $x^{*}(m)=(m / n)(h-g(m))$. In addition, for all high $m$ such that relief is given, the utility of each individual will be higher than under the policy of no relief; otherwise the utility of each individual will be the same as under the policy of no relief.

Notes. The condition (25) showing when it is beneficial for the government to reduce the amount of the public good and give relief is that the marginal utility of relief, $u^{\prime}\left(y_{0}-t^{*}-(m / n) h\right)$, exceeds the social marginal utility of the public good, $n v^{\prime}\left(n t^{*}\right)$. As will be seen, this condition must sometimes be satisfied because the tax $t^{*}$ is optimal given the policy of no relief.

The policy of government relief reduces the payments made to accident victims due to private risk-sharing contracts. In particular, in the absence of relief, an accident victim receives $(1-m / n) h$, but given the policy of relief, he receives $(1-m / n)(h-g(m))$; hence he receives $(1-m / n) g(m)$ less through private risk-sharing. Still, the total compensation of an accident victim rises by $(\mathrm{m} / \mathrm{n}) g(\mathrm{~m})$ on account of the policy of relief.

Proof. Consider $m$ for which

$$
u^{\prime}\left(y_{0}-t^{*}-(m / n) h\right)>n v^{\prime}\left(n t^{*}\right)=\sum_{m} p_{m} u^{\prime}\left(y_{0}-t^{*}-(m / n) h\right) ;
$$


this is a set of $m$ above a threshold level since $u^{\prime}\left(y_{0}-t^{*}-(m / n) h\right)$ is increasing in $m$. Call this set $G$, as it will be the accident events for which the government will give relief. Note that the probability of $G$ must be positive: it was assumed that at least two different accident events $m$ occur with positive probability, implying that $u^{\prime}\left(y_{0}-t^{*}-(m / n) h\right)>\sum_{m} p_{m} u^{\prime}\left(y_{0}-t^{*}-(m / n) h\right)$ must hold for at least one accident event, namely, that with the highest $m$ that has positive probability.

For each $m$ in $G$, let $g(m)$ be any positive $g$ obeying

$$
u^{\prime}\left(y_{0}-t^{*}-(m / n) h+(m / n) g\right) \geq n v^{\prime}\left(n t^{*}-m g\right) \text {. }
$$

That there exist positive $g$ obeying (26) follows from (25) and continuity of $u^{\prime}$ and $v^{\prime}$ in their arguments. Under this policy in which, for $m$ in $G, g(m)>0$ obeys (26) and $g(m)=0$ for other $m$, I claim that individuals will be better off.

To establish this result, let us first solve for the optimal risk-sharing contract given the government policy. Under a contract, the expected utility of each person would be

$$
\begin{aligned}
& \sum_{m} p_{m}\left[(1-(m / n)) u\left(y_{0}-t^{*}-x(m)\right)+(m / n) u\left(y_{0}-t^{*}-h+g(m)+r(m)\right)+\right. \\
& \left.v\left(n t^{*}-m g(m)\right)\right] .
\end{aligned}
$$

The optimal contract maximizes (27) over $x(m)$ and $r(m)$ subject to (17), which is equivalent to maximizing

(28) $(1-(m / n)) u\left(y_{0}-t^{*}-x(m)\right)+(m / n) u\left(y_{0}-t^{*}-h+g(m)+r(m)\right)$

for each $m$, subject to (17). ${ }^{23}$ Substituting for (17), the problem is to maximize

(29) $(1-(m / n)) u\left(y_{0}-t^{*}-x(m)\right)+(m / n) u\left(y_{0}-t^{*}-h+g(m)+(n-m) x(m) / m\right)$

over $x(m)$ for each $m$. The first-order condition for the optimal $x(m)$ is

(30) $u^{\prime}\left(y_{0}-t^{*}-x(m)\right)=u^{\prime}\left(y_{0}-t^{*}-h+g(m)+(n-m) x(m) / m\right)$, which implies that $y_{0}-t^{*}-x(m)=y_{0}-t^{*}-h+g(m)+(n-m) x(m) / m$, so that $x^{*}(m)=(m / n)(h-g(m))$ and thus that $r^{*}(m)=(1-m / n)(h-g(m))$. This also implies that the final wealth of each individual will be $y_{0}-t^{*}-(m / n)(h-g(m))$.

\footnotetext{
${ }^{23}$ Note that $v\left(n t^{*}-m g(m)\right)$ does not enter into (28) because the term does not depend on the risk-sharing contract.
} 
It follows from the above that the utility of each individual conditional on the occurrence of an accident event $m$ is

$$
u\left(y_{0}-t^{*}-(m / n) h+(m / n) g(m)\right)+v\left(n t^{*}-m g(m)\right)
$$

If $m$ is not in $G$, then since $g(m)=0$, (31) is $u\left(y_{0}-t^{*}-(m / n) h\right)+v\left(n t^{*}\right)$, which is the utility in the absence of the policy of relief.

If $m$ is in $G$, then since $g(m)>0$, I claim that

$$
\begin{aligned}
& u\left(y_{0}-t^{*}-(m / n) h+(m / n) g(m)\right)+v\left(n t^{*}-m g(m)\right)>u\left(y_{0}-t^{*}-(m / n) h\right)+ \\
& v\left(n t^{*}\right)
\end{aligned}
$$

meaning that utility is higher than in the absence of relief. This will prove the claim that the policy of relief raises expected utility, for the probability of an $m$ in $G$ is positive, as I showed above. Now to demonstrate (32), consider the function (33) $\left.f(g)=u\left(y_{0}-t^{*}-(m / n) h+(m / n) g\right)\right)+v\left(n t^{*}-m g\right)$.

We have

$$
\left.f^{\prime}(g)=(m / n)\left[u^{\prime}\left(y_{0}-t^{*}-(m / n) h+(m / n) g\right)\right)-n v^{\prime}\left(n t^{*}-m g\right)\right],
$$

which is positive at $g=0$ by (25), greater or equal to zero at $g(m)$ by (26), and must be positive in $[0, g(m))$ since $f^{\prime \prime}(g)<0$. Since $f^{\prime}(g)$ is positive in $[0, g(m))$, we know that $f(g(m))>f(0)$, but this inequality is equivalent to (32). Q. E. D.

Although the government can improve on the best policy of no relief by giving positive relief to accident victims whenever the number of accidents is relatively high, such an adjusted policy cannot result in the first-best outcome. That is because the optimal level of taxes $t^{*}$ under the policy of no relief is set to maximize social welfare over the entire range of possible accidents states (see (24)). Therefore, $t^{*}$ is too low to finance the first-best level of public goods when the number of accidents is low. It would be in the collective interest of individuals to alter taxes to cure this problem, and they can do so: If taxes are set equal to the highest level that could possibly be needed for public goods, then the first best outcome can in principle be achieved under an appropriate policy of relief. In particular, we have 
Proposition 4. Suppose that the tax is $z^{*}(0) / n$ and that the government gives positive relief to accident victims in all accident events $m \geq 1$, where the relief is $g(m)=\left(z^{*}(0)-z^{*}(m)\right) / m$. Then the optimal risk-sharing contract will be $x(m)=(m / n)(h-g(m))$ and $r(m)=((1-(m / n))(h-g(m))$, the wealth of each individual in accident state $m$ will be $y_{0}-z^{*}(m) / n-(m / n) h$, and the first-best outcome will be achieved.

Notes. The explanation for this result is that the tax revenues are $n z^{*}(0) / n$ $=z^{*}(0)$, so support the optimal level of public goods if there are no accidents. If there are a positive number $m$ of accidents, the first-best level of public goods can be achieved if the government reduces expenditures on public goods suitably; first-best risk-sharing will then occur when the government distributes the savings from the reduction in public goods expenditures to accident victims and optimal contracts for risk-sharing are made.

Proof. If the tax is $z^{*}(0) / n$ and $g(m)=\left(z^{*}(0)-z^{*}(m)\right) / m$ for $m \geq 1$, then the level of public goods will be first-best for every $m$, since expenditures on public goods will be

$$
Z^{*}(0)-m g(m)=Z^{*}(0)-m\left(Z^{*}(0)-Z^{*}(m)\right) / m=z^{*}(m) .
$$

Risk-sharing contracts will be $x(m)=(m / n)(h-g(m))$ and $r(m)=((1-(m / n))(h-$ $g(m)$ ) by the argument given in the proof of Proposition 3. Hence, the wealth of each person in accident event $m$ will be

$$
\begin{aligned}
y_{0}-t-(m / n)(h-g(m)) & =y_{0}-z^{*}(0) / n-(m / n)\left(h-\left(z^{*}(0)-z^{*}(m)\right) / m\right) \\
& \left.=y_{0}-(m / n) h-z^{*}(m)\right) / n=y^{*}(m) .
\end{aligned}
$$

Accordingly, the first-best outcome is achieved. Q. E. D.

\subsection{Subsidy of private risk-sharing contracts. I now consider government} subsidy of risk-sharing contracts. Subsidization can be accomplished ex ante-by the government giving a subsidy amount to each individual in period 1 that is based on his risk-sharing contract. Subsidization can also be made ex post-by 
the government adding to the payments made to accident victims in period 2 in a way that depends on the risk-sharing contract.

Let us first examine ex ante subsidies. Assume that

$s=$ subsidy amount paid in period 1 to an individual who makes a risk-sharing contract,

In particular, let

$\sigma_{m}=$ subsidy rate for the payment $x(m)$ under the risk-sharing contract; $\sigma_{m} \geq 0 ;$ and suppose that

$$
s=\sum_{m} \sigma_{m} p_{m} X(m) .
$$

Hence, the ex ante subsidy is a weighted average of expected payments $p_{m} x(m)$ made under the risk-sharing contract. Under an ex ante subsidy, the expected utility of each individual will be

$$
\begin{aligned}
& \sum_{m} p_{m}\left[(1-(m / n)) u\left(y_{o}-t+s-x(m)\right)+(m / n) u\left(y_{o}-t+s-h+r(m)\right)+\right. \\
& v(n t-n s)] .
\end{aligned}
$$

Note in (38) that since each person receives the subsidy s due to his risk-sharing contract, the total expenditure of the government is $n s$, which reduces the amount available for public goods. ${ }^{24}$ We have

Proposition 5. An ex ante subsidy of risk-sharing contracts cannot improve welfare over a policy of no government relief, but an ex ante subsidy can lead to the same level of welfare.

Notes. The reason that an ex ante subsidy cannot raise welfare is that, for welfare to be enhanced, government expenditures on public goods must be a function of the number of accidents $m$, whereas this does not happen under a subsidy paid in period 1. At best, then, an ex ante subsidy could lead to the same level of welfare as that achievable under the policy of no relief when the tax is optimally chosen. That the subsidy does lead to this level of welfare may at first

\footnotetext{
${ }^{24}$ Expression (38) implicitly reflects the symmetry assumption, for $n s$ is subtracted rather
} than a sum of different subsidy amounts for different individuals. 
seem counterintuitive because one might expect the subsidy to distort the sharing of risk. Indeed, it is true that the subsidy usually distorts the sharing of risk. (As I show in the proof, the subsidy results in an inefficient sharing of risk whenever $M$, defined below, is unequal to $n v^{\prime}(n t-n s)$.) However, if the tax is chosen appropriately, the subsidy will not turn out to distort risk-sharing, essentially because the risk-sharing contract that is chosen by individuals is a collective contract.

Proof. The risk-sharing contract that individuals choose maximizes (38) over the $x(m)$ subject to (17) and (37). From (38), it is clear that the public goods expenditures are fixed and equal to $n t-n s$; they are not a function of the accident event $m$. The government can achieve at least the level of welfare that is achieved with the subsidy under a policy of no relief (and no subsidy) simply by setting the tax equal to $t-s$. For then public expenditures will be $n t-n s$ and the risk-sharing accomplished by the contract individuals choose will be socially optimal given the level of public expenditures, by the logic of Proposition 2.

To show that it is possible using a subsidy to achieve the level of welfare possible under no relief when taxes are optimally set at $t^{*}$ as described in Proposition 2, let me first consider the determination of the privately optimal risksharing contract given the subsidy. Making use of (18), the contract is obtained by maximizing

$$
\begin{aligned}
& \sum_{m} p_{m}\left[(1-(m / n)) u\left(y_{o}-t+s-x(m)\right)+(m / n) u\left(y_{o}-t+s-h+\right.\right. \\
& [(n-m) / m] x(m))]+v(n t-n s)
\end{aligned}
$$

over the $x(m)$ subject to (37). The derivative of (39) with respect to a particular $x(m)$, which I will call $x(j)$ here, is

$$
\text { (40) } \begin{aligned}
& p_{j}\left\{-(1-(j / n)) u^{\prime}\left(y_{o}-t+s-x(j)\right)+[(n-j) / j](j / n) u^{\prime}\left(y_{o}-t+s-h+[(n-\right.\right. \\
& j) / j] x(j))\}+\sigma_{j} p_{j} \sum_{m} p_{m}\left[(1-(m / n)) u^{\prime}\left(y_{o}-t+s-x(m)\right)+(m / n) u^{\prime}\left(y_{o}-t+s-\right.\right. \\
& h+[(n-m) / m] x(m))]-n \sigma_{j} p_{j} v^{\prime}(n t-n s) .
\end{aligned}
$$


The first term in (40) is the direct effect of increasing $x(j)$ on expected utility in the accident event $j$; the second term is the income effect due to the increase in the subsidy; and the third term is the reduction in public goods due to the expenditure on the subsidy. Setting the expression in (40) equal to zero and dividing by $p_{j}$ gives the first-order condition

$$
\begin{aligned}
& {[(n-j) / j](j / n) u^{\prime}\left(y_{o}-t+s-h+[(n-j) / j] x(j)\right)+\sigma_{j}\left(M-n v^{\prime}(n t-n s)\right)} \\
& =(1-(j / n)) u^{\prime}\left(y_{o}-t+s-x(j)\right)
\end{aligned}
$$

where $M$ stands for $\sum_{m} p_{m}\left[(1-(m / n)) u^{\prime}\left(y_{o}-t+s-x(m)\right)+(m / n) u^{\prime}\left(y_{o}-t+s-\right.\right.$ $h+[(n-m) / m] x(m))]$, the expected marginal utility of income. Condition (41) simplifies to

(42) $u^{\prime}\left(y_{o}-t+s-h+[(n-j) / j] x(j)\right)+\sigma_{j}[n /(n-j)]\left(M-n v^{\prime}(n t-n s)\right)=u^{\prime}\left(y_{o}-t\right.$ $+s-x(j))$.

Note therefore the significance of the sign of $\left(M-n v^{\prime}(n t-n s)\right)$, the expected marginal utility of income minus the social marginal utility from public goods. If $M>n v^{\prime}(n t-n s)$, then $u^{\prime}\left(y_{o}-t+s-h+[(n-j) / j] x(j)\right)<u^{\prime}\left(y_{o}-t+s-x(j)\right)$, so that $y_{o}-t+s-h+[(n-j) / j] x(j)>y_{o}-t+s-x(j)$; if $M<n v^{\prime}(n t-n s)$, then $y_{o}-$ $t+s-h+[(n-j) / j] x(j)<y_{o}-t+s-x(j)$; and if $M=n v^{\prime}(n t-n s)$, then $y_{o}-t+$ $s-h+[(n-j) / j] x(j)=y_{o}-t+s-x(j)$.

Now to demonstrate the claim, let (43) $s^{*}=\sum_{m} \sigma_{m} p_{m}(m / n) h$

for any subsidy scheme of the $\sigma_{m}$. This is the subsidy payment that a person would receive if he made the optimal risk-sharing contract in the absence of relief, for from Proposition 2 we know that $x^{*}(m)=(m / n) h$. Let the tax be

$$
t^{* *}=t^{*}+s^{*}
$$

where $t^{*}$ is the optimal tax in Proposition 2. I assert that given $t^{* *}$, the same outcome described in Proposition 2 will be implemented under the subsidy scheme. This follows immediately from two observations: (i) If the risk-sharing contract chosen by individuals is $x^{*}(m)=(\mathrm{m} / \mathrm{n}) h$, then by (43) and (44), public 
goods expenditures must be $n t^{* *}-n s^{*}=n t^{*}$ and the outcome in Proposition 2 will thus be achieved. (ii) The risk-sharing contract chosen by individuals will be $x^{*}(m)$, for when public goods expenditures are $n t^{*}$, equation (24) must hold. In particular, (24) states that $\sum_{m} p_{m} u^{\prime}\left(y_{0}-t^{*}-(m / n) h\right)=n v^{\prime}\left(n t^{*}\right)$. Accordingly, if $x(m)=(m / n) h$, then the first-order condition (42) will be satisfied at $x(m)=$ $(m / n) h$, for then (24) means that $M=n v^{\prime}\left(n t^{* *}-n s^{*}\right)=n v^{\prime}\left(n t^{*}\right)$. Q. E. D.

Next consider ex post subsidies of risk-sharing contracts. Under an ex post subsidy, I assume that if $m$ accidents occur, the government adds $\sigma_{m}$ dollars to each dollar paid under a risk-sharing contract by those who are not accident victims. Hence, the extra amount received by each accident victim is

$$
\sigma_{m}(n-m) x(m) / m
$$

and the expenditure of the government on the subsidy is

$$
\sigma_{m}(n-m) x(m)
$$

Thus, an ex post subsidy resembles government relief to accident victims, suggesting that such a subsidy can improve welfare over a policy of no relief. The two propositions that follow validate this intuition.

Proposition 6. An ex post subsidy of risk-sharing contracts can improve welfare over a policy of no government relief. In particular, suppose that the tax is the optimal tax $t^{*}$ under the policy of no relief. Then a welfare-improving ex post subsidy scheme exists involving a positive subsidy for accident events $m$ where $m$ is sufficiently high, determined by (25), as in Proposition 3.

Notes. The logic underlying this conclusion is similar to that of Proposition 3. Namely, when $m$ obeys (25), the marginal utility of income exceeds the social marginal utility of the public good, implying that a reduction in public goods accomplished by a subsidy will be socially beneficial, other things being equal. A complication arises, however, because subsidies tend to distort risk-sharing. Nevertheless, as will be indicated, the first-order welfare loss due to 
the subsidy-related distortion is zero when the subsidy begins to be applied, so that a sufficiently small subsidy will raise welfare.

Proof. Given the definition of ex post subsidies, the expected utility of an individual is

$$
\begin{aligned}
& \sum_{m} p_{m}\left[(1-(m / n)) u\left(y_{o}-t-x(m)\right)+(m / n) u\left(y_{o}-t-h+\left(1+\sigma_{m}\right)[(n-\right.\right. \\
& \left.m) / m] x(m))+v\left(n t-\sigma_{m}(n-m) x(m)\right)\right],
\end{aligned}
$$

The optimal contract maximizes (47) over the $x(m)$. Since the choice of $x(m)$ affects only the $m^{\text {th }}$ term in (47), the problem of maximizing (47) over the $x(m)$ reduces to maximizing

$$
\begin{aligned}
& (1-(m / n)) u\left(y_{o}-t-x(m)\right)+(m / n) u\left(y_{o}-t-h+\left(1+\sigma_{m}\right)[(n-m) / m] x(m)\right)+ \\
& v\left(n t-\sigma_{m}(n-m) x(m)\right) .
\end{aligned}
$$

over $x(m)$ for each $m$ individually. For convenience, let me write $x(m)$ in (48) as $x$ and take its derivative with respect to $x$ to obtain,

$$
\begin{gathered}
\text { (49) }-(1-(m / n)) u^{\prime}\left(y_{o}-t-x\right)+\left(1+\sigma_{m}\right)[(n-m) / m](m / n) u^{\prime}\left(y_{o}-t-h+(1+\right. \\
\left.\left.\sigma_{m}\right)[(n-m) / m] x\right)-\sigma_{m}(n-m) v^{\prime}\left(n t-\sigma_{m}(n-m) x\right) .
\end{gathered}
$$

The first-order condition determining $x$ is thus

$$
\begin{gathered}
\left(1+\sigma_{m}\right)[(n-m) / m](m / n) u^{\prime}\left(y_{o}-t-h+\left(1+\sigma_{m}\right)[(n-m) / m] x\right) \\
=(1-(m / n)) u^{\prime}\left(y_{o}-t-x\right)+\sigma_{m}(n-m) v^{\prime}\left(n t-\sigma_{m}(n-m) x\right),
\end{gathered}
$$

or, after simplification,

$$
\begin{aligned}
& u^{\prime}\left(y_{o}-t-h+\left(1+\sigma_{m}\right)[(n-m) / m] x\right)=u^{\prime}\left(y_{o}-t-x\right) \\
& +\sigma_{m}\left[n v^{\prime}\left(n t-\sigma_{m}(n-m) x\right)-u^{\prime}\left(y_{o}-t-h+\left(1+\sigma_{m}\right)[(n-m) / m] x\right)\right] .
\end{aligned}
$$

Now suppose that $t=t^{*}$, the optimal tax under the no relief policy, as determined in Proposition 2. Choose an $m$ sufficiently high that it is in the set $G$ described in Proposition 3; hence

(52) $u^{\prime}\left(y_{0}-t^{*}-(m / n) h\right)>n v^{\prime}\left(n t^{*}\right)$.

I claim that for this $m$, there exists a positive $\sigma_{m}$ such that the subsidy policy with this $\sigma_{m}$ and all other $\sigma_{i}$ equal to 0 results in higher welfare than the policy of no relief. Showing this claim will obviously demonstrate that some ex post subsidy 
policy dominates the policy of no relief. To prove the claim, it will suffice to show that the derivative of (48) with respect to $\sigma_{m}$ is positive when evaluated at $\sigma_{m}$ $=0$, for all the terms in expected utility other than the $m^{\text {th }}$ are the same as those under the policy of no relief since the $\sigma_{i}$ are 0 for $i \neq m$. Let me rewrite (48) as follows.

(53) $\omega(x(\sigma), \sigma)=(1-(m / n)) u\left(y_{o}-t^{*}-x(\sigma)\right)+(m / n) u\left(y_{o}-t^{*}-h\right.$

$$
+(1+\sigma)[(n-m) / m] x(\sigma))+v\left(n t^{*}-\sigma(n-m) x(\sigma)\right),
$$

where $\omega$ stands for welfare when $m$ accidents occur, $\sigma$ stands for $\sigma_{m}$, and $x(\sigma)$ stands for $x(m)$, which is a function of $\sigma_{m}$ determined implicitly by (51). The derivative of (53) with respect to $\sigma$ is

$$
\begin{aligned}
& +(m / n)(1+\sigma)[(n-m) / m] x^{\prime}(\sigma) u^{\prime}\left(y_{o}-t^{*}-h+(1+\sigma)[(n-m) / m] x(\sigma)\right) \\
& +(m / n)[(n-m) / m] x(\sigma) u^{\prime}\left(y_{o}-t^{*}-h+(1+\sigma)[(n-m) / m] x(\sigma)\right) \\
& -(n-m) x(\sigma) v^{\prime}\left(n t^{*}-\sigma(n-m) x(\sigma)\right)-\sigma(n-m) x^{\prime}(\sigma) v^{\prime}\left(n t^{*}-\sigma(n-m) x(\sigma)\right) .
\end{aligned}
$$

Now at $\sigma=0,(54)$ is

(55) $-x^{\prime}(0)(1-(m / n)) u^{\prime}\left(y_{o}-t^{*}-x(0)\right)$

$+(m / n)[(n-m) / m] x^{\prime}(0) u^{\prime}\left(y_{o}-t^{*}-h+[(n-m) / m] x(0)\right)$

$+(m / n)[(n-m) / m] x(0) u^{\prime}\left(y_{o}-t^{*}-h+[(n-m) / m] x(0)\right)-(n-m) x(0) v^{\prime}\left(n t^{*}\right)$.

But at $\sigma=0$, we know that since there is no subsidy, the risk-sharing contract is such that $x(m)=(m / n) h$ and the wealth of both those who suffer from accidents and those who do not is $y_{o}-t^{*}-(\mathrm{m} / \mathrm{n}) \mathrm{h}$. Hence (55) reduces to

$$
\text { (56) } \begin{aligned}
& -x^{\prime}(0)(1-(m / n)) u^{\prime}\left(y_{o}-t^{*}-(m / n) h\right)+(m / n)[(n-m) / m] x^{\prime}(0) u^{\prime}\left(y_{o}-t^{*}\right. \\
& -(m / n) h)+(m / n)[(n-m) / m](m / n) h u^{\prime}\left(y_{o}-t^{*}-(m / n) h\right)-(n-m)(m / n) h v^{\prime}\left(n t^{*}\right) \\
& =[(n-m) / n](m / n) h u^{\prime}\left(y_{o}-t^{*}-(m / n) h\right)-(n-m)(m / n) h v^{\prime}\left(n t^{*}\right) \\
& =[(n-m) m / n] h\left[u^{\prime}\left(y_{o}-t^{*}-(m / n) h\right) / n-v^{\prime}\left(n t^{*}\right)\right] .
\end{aligned}
$$

The last expression must be positive, due to (52), which completes the proof. What was shown, that the derivative of $\omega(x(\sigma), \sigma)$ with respect to $\sigma$ is positive when evaluated at 0 may be understood as follows. The derivative equals $\omega_{x}(x(\sigma)$, 
$\sigma) x^{\prime}(\sigma)+\omega_{\sigma}(x(\sigma), \sigma)$. But $\omega_{x}(x(\sigma), \sigma)$ must be zero: it is the effect on expected utility given $m$ of transferring wealth from nonvictims to victims starting from the optimal contract when there is no subsidy; and under that optimal contract, wealth for nonvictims and victims is the same, meaning that there is no first-order effect from transferring additional wealth between them. Hence, the derivative reduces to $\omega_{\sigma}(x(\sigma), \sigma)$, the direct effect of the subsidy, which is to shift wealth from public goods expenditures to individuals. Since $m$ is high, in the set $G$ guaranteeing (52), this must be beneficial. Q. E. D.

Finally, let me show that the first-best outcome can be achieved under a subsidy policy if the tax is raised from $t^{*}$, the optimal tax under the policy of no relief, to the level sufficiently high to allow the ideal level of public goods if there are no accidents.

Proposition 7. Suppose that the tax is $z^{*}(0) / n$. Then there exists an ex post subsidy policy under which the first-best outcome will be achieved.

Notes. This explanation for this result is similar to that for Proposition 4. If the tax is as stated, then tax revenues are $z^{*}(0)$, so the optimal level of public goods will be supplied if there are no accidents. If there are a positive number $m$ of accidents, the first-best level of public goods will be achieved if the government reduces expenditures on public goods appropriately, which will happen if its positive subsidy rate is chosen to accomplish that objective. However, when the subsidy rate is positive, one might expect risk-sharing to be distorted, preventing achievement of the first-best outcome. As the proof shows, though, risk-sharing turns out not to be distorted if the subsidy policy is chosen optimally.

Proof. Assume that the tax $t$ is $z^{*}(0) / n$. Then when $m=0$, the first-best outcome will be achieved. Now suppose that, for any positive $m$, we have

$$
\sigma_{m}(n-m) x(m)=z^{*}(0)-z^{*}(m) .
$$


Then public goods will be first-best given $m$, since the left-hand side is government expenditures on the subsidy, which will reduce government expenditures on public goods from $z^{*}(0)$ to $z^{*}(m)$. Suppose also that $\sigma_{m}$ and $x(m)$ are such that

$$
y_{o}-z^{*}(0) / n-x(m)=y_{o}-z^{*}(0) / n-h+[(n-m) / m]\left(1+\sigma_{m}\right) x(m) .
$$

This means that nonaccident victims have the same wealth as accident victims, and thus that risk-sharing will also be first-best. Hence, if I can show that there exist $\sigma_{m}$ and $x(m)$ satisfying (57) and (58) and that $x(m)$ will also be chosen by individuals - which is to say, that $x(m)$ satisfies the first-order condition (51) - I will have demonstrated that the first-best outcome can be achieved under an ex post subsidy.

Note first that (57) and (58) imply that

$$
y_{o}-z^{*}(0) / n-x(m)=y_{o}-z^{*}(m) / n-(m / n) h .
$$

This must be true, for (57) implies that the total wealth available for individuals to consume is $n y_{o}-z^{*}(m)-m h$, which means that the per person wealth for consumption is $y_{o}-z^{*}(m) / n-(m / n) h$, and (58) implies that each person must consume this amount.

Now to show that (51), will be satisfied, observe that (57) and (59) imply that (51) reduces to $n v^{\prime}\left(z^{*}(m)\right)-u^{\prime}\left(y_{o}-z^{*}(m) / n-(m / n) h\right)=0$, and this must hold by (9).

It remains to show that there exist positive $\sigma_{m}$ and $x(m)$ obeying (57) and (58). Solving them, we find that

(60) $x(m)=\left(m h-\left(z^{*}(0)-Z^{*}(m)\right) / n\right.$,

(61) $\sigma_{m}=n\left(z^{*}(0)-z^{*}(m)\right) /\left[(n-m)\left(m h-\left(z^{*}(0)-z^{*}(m)\right)\right.\right.$.

These are both positive, for (15) implies that $z^{*}(0)-z^{*}(m)<m h$. Q. E. D.

2.6 Adjustment of taxes. To this point, I have discussed how government relief for accident victims and subsidy of risk-sharing contracts can be employed 
to raise social welfare. Another way for the government to raise social welfare is to reduce the tax as the number of accidents increases.

Proposition 8. Suppose that the tax is imposed at time 2 and equals $z^{*}(m) / n$ —or equivalently that the tax is imposed at time 1 but is adjusted at time 2 , through a surtax or a credit, such that the final tax is $z^{*}(m) / n$. Then the risksharing contract will be $x(m)=(m / n) h$ and $r(m)=((1-(m / n)) h$, the wealth of each individual in accident event $m$ will be $y_{0}-z^{*}(m) / n-(m / n) h$, and the first-best outcome will be achieved.

Notes. It is evident that there is no need for relief or subsidy of risksharing if taxes depend on the number of accidents, for such adjustment of taxes allows the level of wealth available for consumption to be a function of the number of accidents, and privately-optimal risk sharing then results in the socially best outcome.

Proof. The tax results in the first-best level of the public good in each accident event $m$ by assumption. That the risk-sharing contract is as claimed follows essentially from the proof of Proposition 2. Hence, the first-best outcome is achieved. Q. E. D.

\section{Concluding Remarks}

To recapitulate, it was shown in the world of a simple model that the government can raise social welfare by giving aid when substantial, especially correlated, adverse outcomes occur. The reason was that privately optimal risksharing does not lead to full protection against large risks, whereas the government can divert resources from provision of public goods to relief for victims of adverse outcomes.

Three methods of government support were beneficial. One was direct relief to accident victims. A second was ex post subsidy of risk-sharing arrangements (such as federal participation in the coverage of flood insurance 
claims ${ }^{25}$ ). Ex ante subsidy of risk-sharing agreements (illustrated by the earthquake insurance program in California ${ }^{26}$ ), however, was not socially advantageous because it does not lead to the shifting of government-controlled resources to individuals as a function of the extent of accident losses. The third type of beneficial aid was income tax adjustment in the light of accidents. ${ }^{27}$ These three forms of government help were equivalent in the sense that they could each be employed to achieve first-best outcomes.

However, these types of government aid would not be equivalent in the face of a number of factors that were not reflected in the model. For example, the factor of moral hazard might be addressed better by a tailored government-supported insurance program than by direct government relief or tax adjustment. Conversely, problems stemming from the underestimation of risks might be better met by direct relief or tax adjustment, as these forms of government aid do not depend on the accuracy of individuals’ perceptions of risk.

${ }^{25}$ The federal flood insurance program involves both ex post subsidy, in that it can resort to borrowing from the Treasury, and ex ante subsidy of premiums. See FEMA (2002), pp. 22-28.

26 The insurance offered under the auspices of the California Earthquake Authority incorporates an implicit ex ante subsidy of premiums because the Authority does not pay taxes. However, the program of the Authority does not reflect an ex post subsidy in that it cannot draw on the state's funds if its assets are not sufficient to pay the claims made in a large earthquake. See www.earthquakeauthority.com.

${ }^{27}$ The income tax system in fact has a feature that gives relief from accident losses: casualty losses may be deducted from taxable income. However, the casualty loss deduction is not conditioned on whether the losses are correlated (and thus not on the availability or price of insurance coverage). 


\section{References}

Arrow, Kenneth J., and Robert C. Lind. 1970. "Uncertainty and the Evaluation of Public Investment Decisions.” American Economic Review, 60(3): 364378.

Cook, Philip, and Donald Graham. 1977. "The Demand for Insurance and Protection: The Case of Irreplaceable Commodities.” Quarterly Journal of Economics, 99(1): 143-156.

Cummins, J. David. 2006. "Should the Government Provide Insurance for Catastrophes?” Federal Reserve Bank of St. Louis Review, 88(4): 337379.

Dionne, Georges, Neil Doherty, and Nathalie Fombaron. 2000. “Adverse Selection in Insurance Markets," in Georges Dionne, ed., Handbook of Insurance. Boston: Kluwer, ch. 7.

Federal Emergency Management Agency. 2002. National Flood Insurance Program. Program Description. http://www.fema.gov/about/programs/nfip/index.shtm.

Froot, Kenneth, ed. 1999. The Financing of Catastrophe Risk. Chicago: University of Chicago Press.

Froot, Kenneth A. 2001. "The Market for Catastrophe Risk: A Clinical Examination.” Journal of Financial Economics, 60(2-3): 529-571.

Jaffee, Dwight M., and Thomas Russell. 1997. "Catastrophe Insurance, Capital Markets, and Uninsurable Risks.” Journal of Risk and Insurance, 64(2): 205-230.

Kaplow, Louis. 1991. “Incentives and Government Relief for Risk.” Journal of Risk and Uncertainty, 4(2): 167-175.

Kunreuther, Howard, Ginsburg, R., Miller, L., Sagi, P., Slovic, Paul, Borkin, B., Katz, N. 1978. Disaster Insurance Protection. New York: Wiley.

Moss, David A. 1999. "Courting Disaster? The Transformation of Federal Disaster Policy Since 1803,” in Kenneth Froot, ed., The Financing of Catastrophe Risk. Chicago: University of Chicago Press, ch. 8. 
Priest, George L. 1996. "The Government, the Market, and the Problem of Catastrophic Loss.” Journal of Risk and Uncertainty, 12(2-3): 219-237. 